\title{
Transport of warm Upper Circumpolar Deep Water onto the western Antarctic Peninsula continental shelf
}

\author{
D. G. Martinson ${ }^{1,2}$ and D. C. McKee ${ }^{1,2}$ \\ ${ }^{1}$ Division of Ocean and Climate Physics, Lamont-Doherty Earth Observatory of Columbia University, 61 Route 9W, \\ Palisades, NY 10964, USA \\ ${ }^{2}$ Department of Earth and Environmental Sciences, Columbia University, New York, NY USA
}

Correspondence to: D. G. Martinson (dgm@ldeo.columbia.edu)

Received: 31 October 2011 - Published in Ocean Sci. Discuss.: 15 December 2011

Revised: 14 April 2012 - Accepted: 2 May 2012 - Published: 10 July 2012

\begin{abstract}
Five thermistor moorings were placed on the continental shelf of the western Antarctic Peninsula (between 2007 and 2010) in an effort to identify the mechanism(s) responsible for delivering warm Upper Circumpolar Deep Water (UCDW) onto the broad continental shelf from the Antarctic Circumpolar Current (ACC) flowing over the adjacent continental slope. Historically, four mechanisms have been suggested: (1) eddies shed from the ACC, (2) flow into the cross-shelf-cutting canyons with overflow onto the nominal shelf, (3) general upwelling, and (4) episodic advective diversions of the ACC onto the shelf. The mooring array showed that for the years of deployment, the dominant mechanism is eddies; upwelling may also contribute but to an unknown extent. Mechanism 2 played no role, though the canyons have been shown previously to channel UCDW across the shelf into Marguerite Bay. Mechanism 4 played no role independently, though eddies may be advected within a greater intrusion of the background flow.
\end{abstract}

\section{Introduction}

The western Antarctic Peninsula (WAP) is undergoing extraordinary climate change - Earth's most extreme winter atmospheric warming, and severe sea ice and glacial ice loss with $87 \%$ of the marine glaciers in retreat (Cook et al., 2005). Vaughan (2005) notes that the winter warming points to the ocean for the source of heat (the obvious source of heat in the region in winter, when there is no direct radiative forcing at the polar circle, and no warm air masses of any substance advecting through). The WAP is bordered by the Antarctic Circumpolar Current (ACC) that advects a large volume water mass of warm water just below the surface layer known as Upper Circumpolar Deep Water (UCDW). This water mass supplies heat and nutrients to the WAP continental shelf, playing an important role in the marine ecosystem of the region (Ducklow et al., 2012). Martinson et al. (2008) documented an increase in ocean heat content along the WAP margin. The heat from this water mass and its underlying Lower Circumpolar Deep Water (LCDW) travels across the continental shelf via deep canyons, serving as conduits to the coastline where it can reach the underside of the ice shelves, contributing to their melt and raising sea level. This passage through the canyons has been studied at some length. It is the intention of this study to look at how the UCDW makes its way to the shelf waters above these canyons (the "nominal" shelf) where it impacts the biology and ecosystem of the region (e.g., Ducklow et al., 2012).

These needs motivated the deployment of the International Polar Year Synoptic Antarctic Slope-Shelf Interaction (IPY SASSI) mooring array on the shelf in this particular location (the WAP). Further, this location is ideal given that it is situated in the heart of the extensive (20 year) gridded data set of the Palmer Long Term Ecological Research project (Pal LTER; Smith et al., 1995). This paper describes the array and findings. 


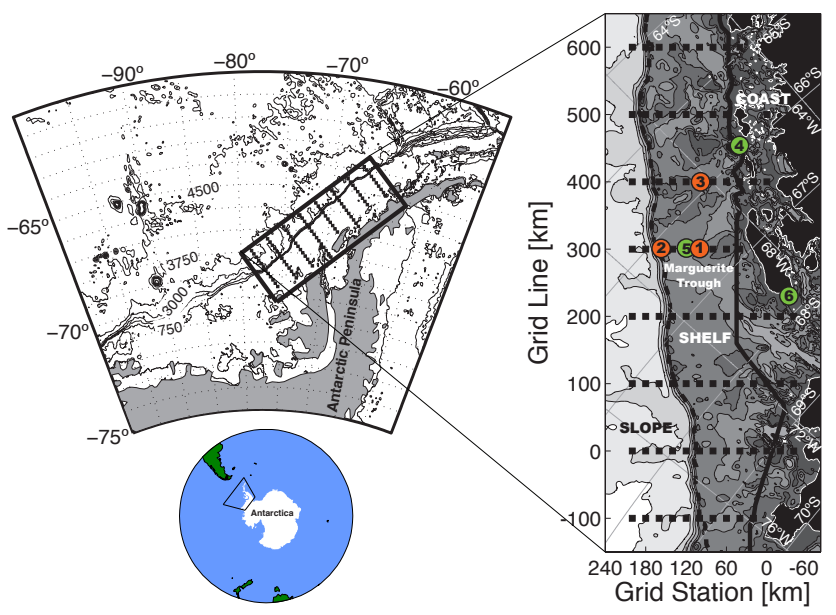

Fig. 1. Location of LTER marine sampling grid from which data for this study have been acquired. Shipboard (CTD) sampling locations shown as solid squares. Numbered circles in sample grid (right panel) show the various mooring locations during the years of data included in this study (2007-2010); Table 1 lists the specific mooring locations for each year. Mooring \#1 was deployed in 2007 as part of the LTER project. All others in 2008 and beyond as part of the IPY SASSI project (never more than five moorings deployed in any one year). Gold colored mooring sites are the most consistently occupied and the primary focus of this study, green ones less so. Marguerite Trough (labeled) cuts across the center of the shelf into Marguerite Bay. Grid bathymetry shaded between contours every $150 \mathrm{~m}$ from $200 \mathrm{~m}$ until 750 , and then at $750 \mathrm{~m}$ intervals until 3750 .

\section{Data}

\subsection{Study region}

Most of the data for this study have been acquired in the LTER marine sampling grid shown in Fig. 1. The LTER project has collected shipboard data since 1991 including every January since 1993.

\subsubsection{Physical setting}

In this study region, as well as most of western Antarctica, the ocean is a source of heat. The warmest water, characterized by a temperature maximum $\left(T_{\max }\right)$, is Upper Circumpolar Deep Water (UCDW) at $\geq 1.7^{\circ} \mathrm{C}$ as delivered to the WAP via the Antarctic Circumpolar Current (ACC). Martinson et al. (2008; hereafter MSISV08) using LTER data through 2004, show that on the WAP continental shelf, the heat content of the sub-surface water column (a 3 water mass mixture dominated by UCDW) has increased. Webb (2011) documents a 50-year warming of UCDW in the ACC as it flows past western Antarctica. As the predominant source of heat and nutrients, UCDW is the obvious water mass to focus on in gauging the slope-shelf interaction.

Other water masses present throughout the region include Winter Water (WW), the remnant deep winter mixed layer water formed by convection driven by brine rejection during winter sea ice growth (so it forms near the freezing point). Though driven by brine rejection, the surface layer being deepened is relatively fresh, so WW is also fresher than the denser deeper waters. The permanent pycnocline (whose stratification is comparable to that of mid-depth waters in extra-polar oceans) is situated between the WW and the UCDW immediately below. Underlying the UCDW is Lower Circumpolar Deep Water (LCDW), a variety of Circumpolar Deep Water (CDW) that is characterized by a salinity maximum $\left(S_{\max }\right)$. In our sampling area, LCDW usually occurs at a depth below the nominal shelf depth, though $T_{\max }$ in UCDW lies just above that nominal depth, allowing it more direct access to the shelf. In those regions where LCDW does make it onto the nominal shelf, it too contributes heat.

The LTER sampling grid overlays the broad continental shelf of the WAP at $\sim 450 \mathrm{~m}$ in depth, running $\sim 200 \mathrm{~km}$ in cross-shelf width and $\sim 400 \mathrm{~km}$ along the WAP (recently extended another $\sim 300 \mathrm{~km}$ further SW down the Peninsula). Sample sites are located on a grid system, delineated by "grid lines" that are $100 \mathrm{~km}$ apart and lie perpendicular to the average coastline. "Grid stations" are spaced every $20 \mathrm{~km}$ along these grid lines across the shelf. Grid lines are labeled according to their position in the grid relative to the original southern-most sample location; grid stations are labeled according to their cross-shelf distance from the average coast. Individual sites are identified as ggg.sss, where ggg is the grid line and sss is the grid station location. For example, site 300.100 , the location of mooring \#1, lies $100 \mathrm{~km}$ offshore on the grid line $300 \mathrm{~km}$ up the peninsula from the southernmost line of the grid, near Alexander Island with 000.000 at $\sim 69.0^{\circ} \mathrm{S}, \sim 73.6^{\circ} \mathrm{W}$; the 300.100 site is $60 \mathrm{~km}$ inshore of mooring \#2 located at 300.160 and it is $100 \mathrm{~km}$ southwest (down the peninsula) of site 400.100 , the location of mooring \#3.

In the WAP, the southern boundary of the ACC, as defined by the southern-most presence of UCDW (Orsi et al., 1995), flows over the continental slope along the shelf break as it does throughout the entire SE Pacific region (Orsi et al., 1995; MSISV08) along the continental rim of the Amundsen-Bellingshausen Seas. This makes warm UCDW directly available to the continental shelf for easy ventilation to the atmosphere and glacial melt on the WAP shelf.

In this important respect, the West Antarctic continental shelf is unique in Antarctica for this spatially-extended proximity of the ACC and delivery of warm UCDW (Fig. 2).

\subsubsection{Shipboard data}

Ocean CTD data were collected every austral summer since 1993, as well as during multiple non-summer cruises (see MSISV08 for detailed description of these data). These data are available in the LTER database (http://pal.lternet.edu/ data/), National Oceanographic Data Center (NODC) and in Martinson's LTER data page (http://www.ldeo.columbia. 

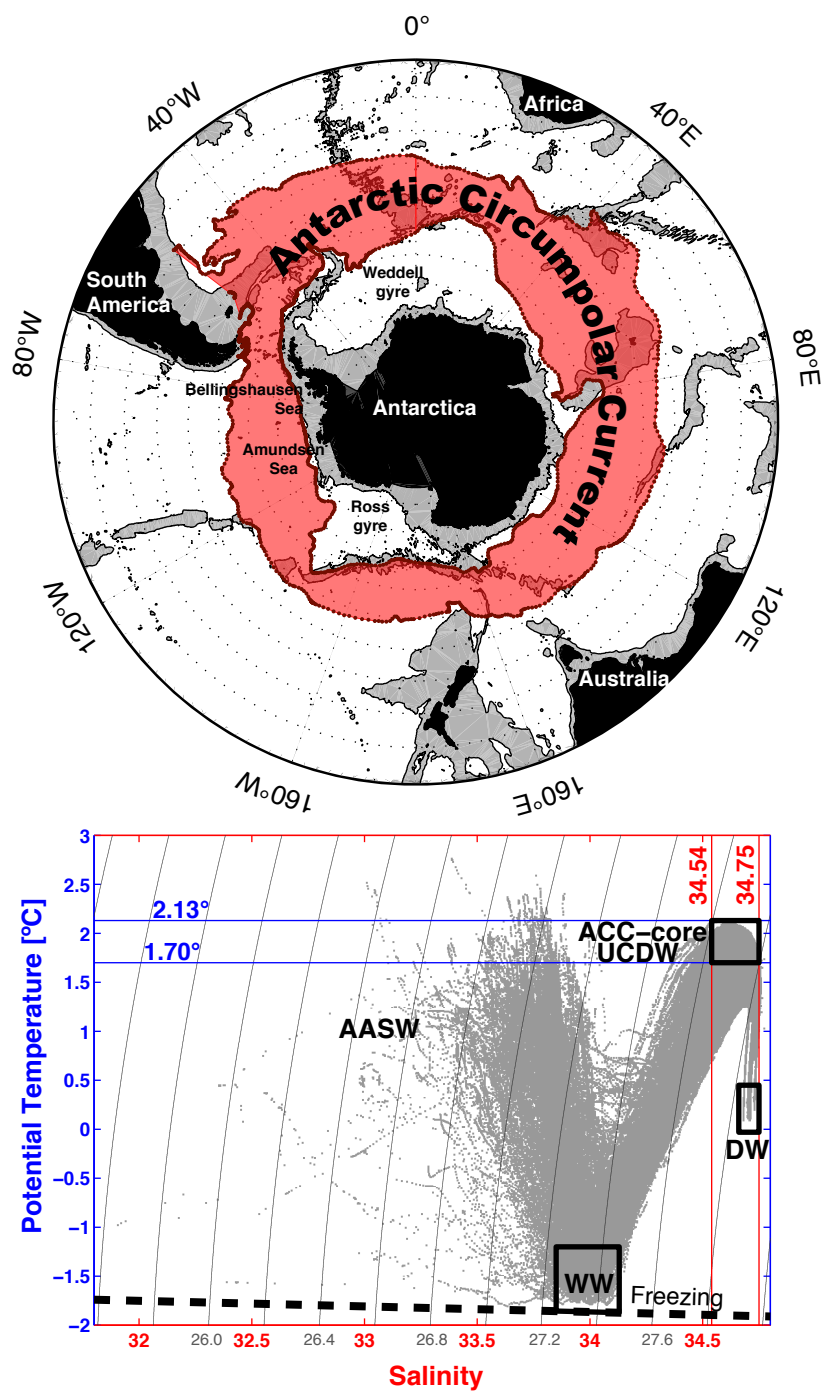

Fig. 2. Location of climatological ACC, transporting warm UCDW. The ACC flows along the slope-shelf break for the entire western Antarctic. Bathymetry shallower than $3 \mathrm{~km}$ is shaded. The lower panel is showing primary water masses in LTER sampling grid (from MSISV08). UCDW is warmest water in water column, occasionally exceeded in temperature by the summer surface layer (AASW).

edu/ dgm/LTER.html), the latter also containing numerous derived products.

\subsubsection{Moorings}

Moorings were deployed (recovered, serviced and redeployed) during the LTER summer (January) annual cruises. Mooring locations were guided by the extensive LTER CTD data as well as results from the 2001-2003 Southern Ocean Global Ecosystem Dynamics project (SO GLOBEC, Hofmann et al., 2004). The former reveal locations where the largest fraction of pure UCDW was distributed on the grid (presumably closest to the location where the UCDW enters the shelf). The latter show that UCDW enters Marguerite Trough (Klinck et al., 2004; Moffat et al., 2009).

Our Lamont thermistor moorings ${ }^{1}$ contain fixed-depth SeaBird (SBE39) thermistors (some with pressure sensors; see Table 1 for details), sampling every 10 (or in 2010, every 15) minutes. SBE39 thermistors possess an initial accuracy of $0.002{ }^{\circ} \mathrm{C}$ and resolution of $0.0001{ }^{\circ} \mathrm{C}$. The vertical spacing and density of the thermistors on the string yield integrated heat content $(Q)$ values that show an average bias of well under $0.1 \%$. Some moorings have current meters whose depths are given in Table 1. Their positions on the string allow us to sample the upper and lower water column, the depths of which are guided by shipboard ADCP data. Mooring data were de-tided using T_TIDE (Pawlowicz et al., 2002), which proves useful for velocities but does little to alter records of $T$. All velocity analyses use the de-tided values.

Mooring locations and years for which data were acquired are given in Table 1. Because of the continued success of moorings \#1, \#2, \#3 and their ideal locations relative to the location of highest fraction of pure UCDW, this study focuses primarily on the data from those moorings.

\section{Analyses - Mechanisms for moving UCDW onto the shelf}

The ACC delivers UCDW to the WAP region and its southern edge flows along the shelf-slope break. Four mechanisms have been suggested for moving the UCDW from the ACC over the slope onto the shelf, the first two based on findings from the Southern Ocean GLOBEC:

1. eddies from the ACC shed onto the shelf (Moffat et al., 2009; Klinck and Dinniman, 2010; St-Laurent et al., 2012);

2. entry into the canyons cutting across the shelf (Klinck et al., 2004), and possible overflow of the canyons filling the overlying shelf waters;

3. upwelling (Prézelin et al., 2000; Martinson et al., 2008);

4. episodic advective diversions (intrusions, flooding events, etc.) of ACC onto shelf (e.g., Dinniman and Klinck, 2004).

We have limited possible mechanisms to those that would be most conducive to mid-depth (as opposed to bottomintensified) heat transport since, it will be shown, this is a characteristic of observed warm anomalies.

\subsection{Eddies}

Moffat et al. (2009) document eddies migrating across the shelf adjacent to Marguerite Trough. We begin evaluation of

\footnotetext{
${ }^{1}$ Moorings designed by Lamont oceanographer Bruce Huber.
} 
Table 1. Mooring locations, years at location and sensor suite. Mooring numbers agree with numbered circles in sample grid of Fig. 1. Current meter abbreviations are S4: InterOcean, and AE: JFE ALEC Electronics - both are electromagnetic current meters.

\begin{tabular}{|c|c|c|c|c|c|c|}
\hline $\begin{array}{l}\text { Mooring } \\
\text { Number }\end{array}$ & $\begin{array}{l}\text { Location/ } \\
\text { Name }\end{array}$ & $\begin{array}{c}\text { Years w/ } \\
\text { Data }\end{array}$ & $\begin{array}{l}\text { \# of } T \\
\text { Depths }\end{array}$ & $\begin{array}{l}\text { \# of } T \\
\text { with } \operatorname{Pr}\end{array}$ & $\begin{array}{c}\text { Current Meter } 1 \\
\text { Depth }\end{array}$ & $\begin{array}{c}\text { Current Meter } 2 \\
\text { Depth }\end{array}$ \\
\hline \multirow[t]{3}{*}{1} & 300.100 & 2007 & 11 & 5 & S4 @ 280 db & $\mathrm{S} 4 @ \sim 84 \mathrm{db}$ \\
\hline & & 2008 & 11 & 5 & S4 @ 279db & - \\
\hline & & 2010 & 15 & 7 & $\mathrm{AE} @ \sim 189 \mathrm{db}$ & AE @ 288db \\
\hline \multirow[t]{3}{*}{2} & 300.160 & 2008 & 17 & 9 & $\mathrm{~S} 4 @ \sim 323 \mathrm{db}$ & - \\
\hline & & 2009 & 17 & 8 & S4 @ 321 db & - \\
\hline & & 2010 & 17 & 8 & $\mathrm{AE} @ \sim 188 \mathrm{db}$ & - \\
\hline \multirow[t]{3}{*}{3} & 400.100 & 2008 & 17 & 8 & S4 @ 290 db & - \\
\hline & & 2009 & 17 & 9 & S4 @ 271 db & - \\
\hline & & 2010 & 14 & 4 & $\mathrm{AE} @ \sim 233 \mathrm{db}$ & $\mathrm{AE} @ \sim 89 \mathrm{db}$ \\
\hline 4 & 460.046 & 2008 & 13 & 6 & $\mathrm{~S} 4 @ \sim 315 \mathrm{db}$ & - \\
\hline 5 & 300.120 & 2010 & 17 & 8 & - & - \\
\hline \multirow[t]{2}{*}{6} & $230 .-035$ & 2008 & 9 & 5 & - & - \\
\hline & & 2009 & 9 & 5 & - & - \\
\hline
\end{tabular}

this mechanism by examination of $Q(t)$ at mooring \#1, located on the northeastern wall of Marguerite Trough, $60 \mathrm{~km}$ inshore of the shelf-slope break where the southern margin of the ACC flows. The heat content of water available to melt ice is $Q=\int_{H}^{\mathrm{wml}} \rho c_{\mathrm{p}}\left[T(z)-T_{\mathrm{f}}\right] d z$ where $\rho$ is density, $\mathrm{c}_{p}$ heat capacity, $T_{f}$ surface freezing point of seawater, and wml top of permanent pycnocline (which is the bottom of the winter mixed layer or base of the WW); $H=415 \mathrm{db}$ and is chosen to be deep enough to represent all heat below wml and above the deepest sensor for all years on moorings \#1 and $\# 2^{2}$.

\subsubsection{Qualitative inspection}

$Q(t)$ shows considerable high-frequency variability that we treat as noise (Fig. 3). We remove the noise by using the first mode of a Karhunen-Loéve transform, performed with an embedding dimension of 19. This forces all of the variance to be described by no more than 19 modes, though for these series, most of the variance is contained in mode 1 over a broad range of embedding dimension values. We prefer this to a more standard filter (e.g., some form of convolution) since the method is data-adaptive. The first mode is used as the smoothed version of $Q(t)$ upon which we perform most of our analyses.

Inspection of the smoothed $Q$ series at mooring site \#1 for each year shows frequent episodic short-lived increases in $Q$, or " $Q$-events" (Fig. 4). Notable is the fact that the rate of $Q$ increase $(d Q / d t)$ appears to be remarkably similar in most cases. One explanation for this is that comparable-sized

\footnotetext{
${ }^{2}$ This differs from MSISV08 who integrate from wml down 300 $\mathrm{db}$; a depth range chosen to include the most CTD-station estimates of $Q$, allowing for the variable shelf bottom depth, and also being big enough to capture a representative amount of heat in the lower water column.
}

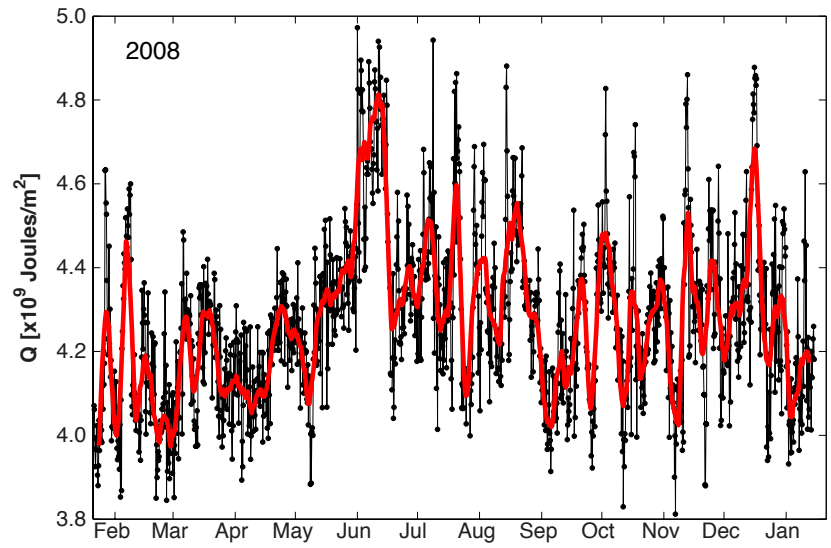

Fig. 3. Time series of $Q$ (dots with black line) for mooring \#1 in 2008 with the gravest mode of the Karhunen-Loéve transform as a filter (red) being the smoothed version used for the analyses.

warm-core eddies move past the mooring site following the same path due to bathymetric tracking.

More telling is the fact that nearly every $Q$-event contains water well above $1.7^{\circ} \mathrm{C}$, (sometimes as high as $2^{\circ} \mathrm{C}$; Figs. 4 and 5). The only water within the LTER sampling grid that occurs at temperatures this high is UCDW as it appears in its unmodified form within the ACC over the continental slope as delivered to the WAP. Nowhere on the continental shelf, except in the core of these events, is water this warm encountered (MSISV08).

The $T_{\max }$ series of Fig. 4 highlights the rapid temporal variability of the water column at mooring \#1, further justifying our need to smooth the $Q$-series and focus on the major "long" lasting features (i.e., $Q$-events). 


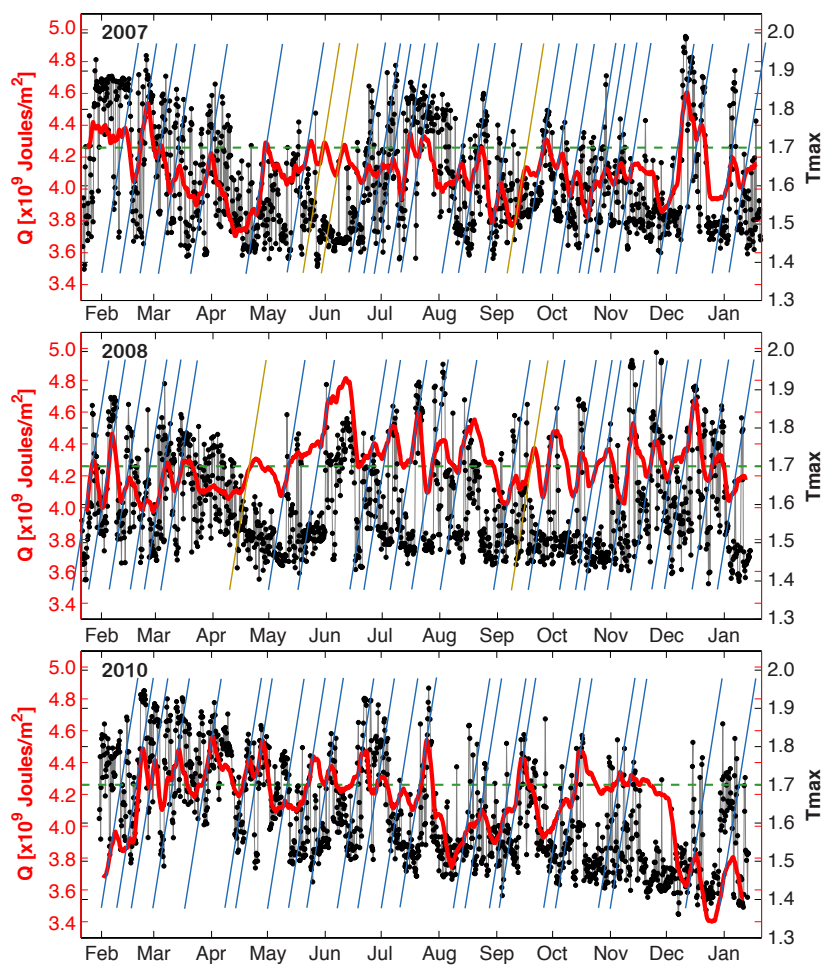

Fig. 4. For the mooring \#1, the gravest mode of $Q$ (solid red line) overlaying $T_{\max }$ (black line with dots). Nearly every $Q$-event shows a core $T_{\max }$ greater than $1.7^{\circ} \mathrm{C}$ (pure UCDW). Blue slanted lines (all of the same slope) show similar $d Q / d t$ for each event. Gold slanted lines (same slope as blue lines) show rare events not coincident with $T_{\max } \geq 1.7^{\circ} \mathrm{C}$.

\subsubsection{Bathymetry tracking}

Besides the consistent $d Q / d t$ and waters with $T_{\max } \geq 1.7^{\circ} \mathrm{C}$ arguing for movement of comparable-sized warm-core eddies, other features point to this conclusion. Mooring \#5 (300.120, Fig. 1) also on the northeast wall is $20 \mathrm{~km}$ offshore of mooring \#1 (300.100), and the $Q$ records at these 2 locations are well correlated $\left(r^{2} \geq 50 \%\right)$ with a lag time of 2.25 days for unsmoothed series and 2.75 days for smoothed $Q$ series. This equates to drift rates along the northern wall of $\sim 0.1 \mathrm{~m} \mathrm{~s}^{-1}$, consistent with velocities measured by the LTER glider fleet (Schofield, personal communication, 2011). Finally, observed current velocities at mooring \#1, if projected as trajectories forward, show a drift following the canyon wall's fork to the northeast (Fig. 6), again consistent with the currents transporting eddies tracking the bathymetry.

\subsubsection{Quantitative analysis}

We combine approaches similar to those of Moffat et al. (2009) and Lilly and Rhines (2002) to quantify the signature of eddies in our mooring observations, focusing on mooring \#1. We identify eddies by examining the velocity data recorded $\left(V_{\text {obs }}\right)$ in the $280 \mathrm{~m}$ current meter (close to the
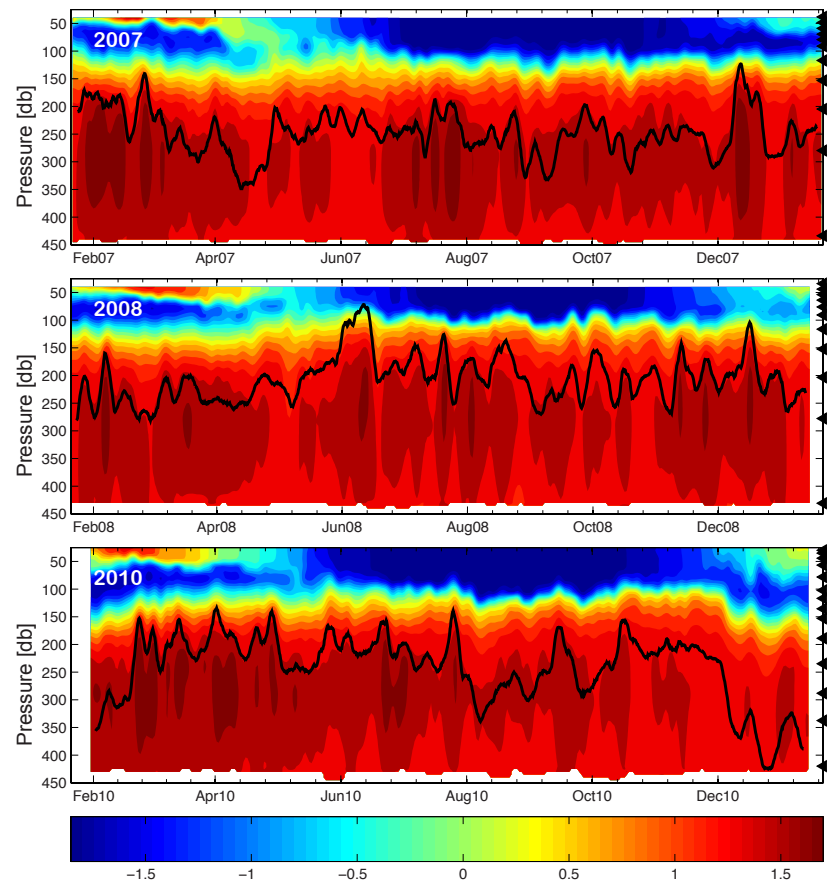

Fig. 5. For the mooring \#1, $T$ as a function of depth and time, with $Q$-series overlain (black line) to show the relationship between $T$ and $Q$-events. $Q$-events clearly coincide with warm (red) deep anticyclonic boluses. Arrows on right ordinate show depths of $T$ sensors. Color bar shows temperature scale.

center of the lower layer warm water boluses seen in Fig. 5) and the 4 closest (in depth) T-sensors. These records are detided and smoothed by a cosine-Lanczos filter centered at $24 \mathrm{~h}$ to remove non-tidal high frequency fluctuations. We define a background drift $V_{\mathrm{bg}}$ (advecting the eddies) as the first mode of a complex singular spectrum analysis with embedding dimension of 121 , providing a series that is everything that is not the eddy rotation itself (a method we are satisfied with based on the clean eddy rotations we detect in the residuals). The eddy velocity, $V_{\mathrm{e}}=V_{\mathrm{obs}}-V_{\mathrm{bg}}$, is then rotated via multiplication with $\mathrm{e}^{-i \varphi}$, where $\varphi$ is the argument of complex $V_{\mathrm{bg}}$. This rotates $V_{\mathrm{e}}$ to be relative to the direction of the background flow $V_{\mathrm{bg}}$ (so that the two components of $V_{\mathrm{e}}$ are now along-stream and cross-stream), most easily allowing identification of rotation independent of the background drift. We assume a rankine vortex model to define the velocity signature of the eddy. Over the time interval that such a vortex occupies the mooring, (1) the cross-stream component of $V_{\mathrm{e}}$ would show an extremum of one sign followed by an extremum of the opposite sign, while (2) the alongstream component would show a fixed-sign signature that increases then decreases in magnitude. The two extrema in the cross-stream component of $V_{\mathrm{e}}$ mark the moments of maximum flow perpendicular to $V_{\mathrm{bg}}$ and therefore the extent of the eddy core. 


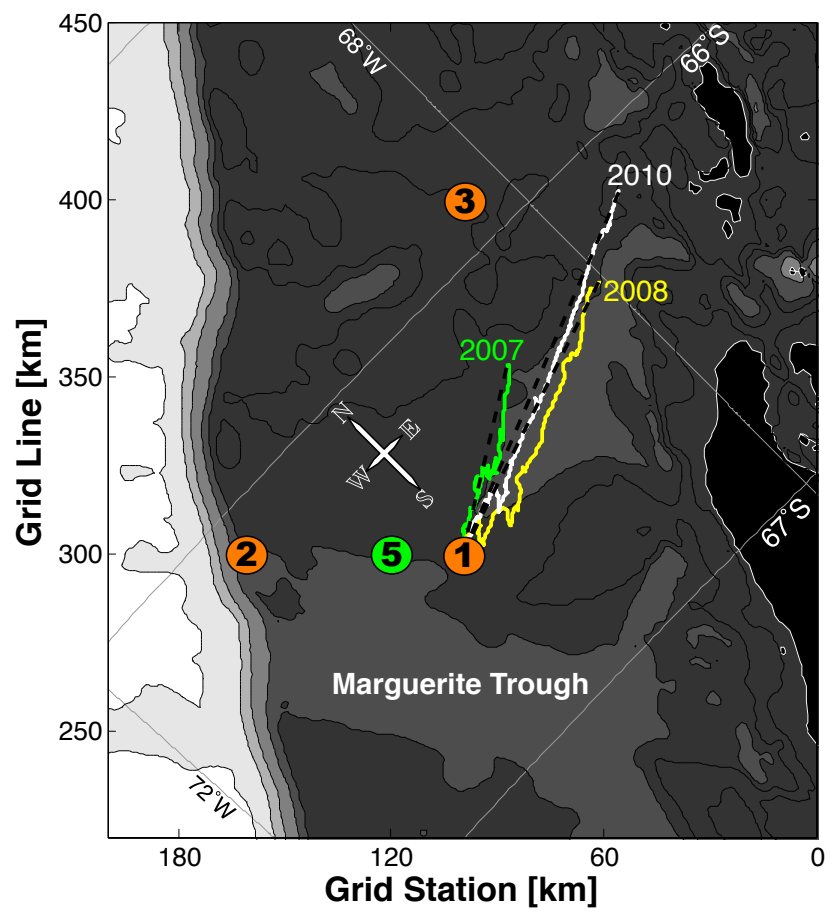

Fig. 6. Progressive vector diagram for the velocities at mooring site \#1. If the flow observed at the mooring at all time steps was extended into a Lagrangian trajectory, the flow would track the northern wall of the Marguerite Trough's NE fork (i.e., track the same bathymetry from the slope-shelf break). The vector lengths are scaled so as to fit onto the image.

Since Fig. 5 suggests that $Q$-events are approximately centered about peaks in $T$, we find all occasions where $T_{\max }$ goes above $1.7^{\circ} \mathrm{C}$ and then descends by at least $0.1^{\circ} \mathrm{C}$ to below $1.7^{\circ} \mathrm{C}$. Specifically, for each such occasion we define $t_{T i}$ (the time where $T_{\max }$ begins increasing towards $1.7^{\circ} \mathrm{C}$ ) and $t_{T \mathrm{e}}$ (the time after $t_{T \mathrm{i}}$ when $T_{\max }$ stops decreasing, is below $1.7^{\circ} \mathrm{C}$ and is at least $0.1^{\circ} \mathrm{C}$ below the previous extremum in $\left.T_{\max }\right)$. The constraint in the magnitude of $\Delta T_{\max }$ is to avoid artificially cutting off a single event. Some of the $Q$-events span more than one such peak in $T_{\max }$.

While the peaks in $T_{\max }$ are found in an automated manner, the velocity records are inspected manually because there can be (though rarely so) more than one eddy within a single peak in $T_{\max }$. Within each peak in $T_{\max }$, augmented by $24 \mathrm{~h}$ in both directions - that is, $\Delta t_{T}=\left(t_{T \mathrm{i}}-24, t_{T \mathrm{e}}+24\right)-$ we examine $V_{\mathrm{e}}$ for the signs of eddy rotation described above (1) a point where $V_{\mathrm{e}}$ moves perpendicular to the background flow, defining the initial eddy presence at the mooring $\left(t_{\mathrm{ei}}\right)$, and (2) that time where $V_{\mathrm{e}}$ is again perpendicular to the background flow, but in the opposite direction, defining the end of the eddy presence at the mooring $\left(t_{\mathrm{ee}}\right)$. To do so, all extrema in the cross-stream component of $V_{\mathrm{e}}$ within $\Delta t_{T}$ are found and the eddy (or eddies) temporal extent(s), $\Delta t_{v}=t_{\mathrm{ee}}-t_{\mathrm{ei}}$, are chosen from this subset of points. A progressive vector diagram

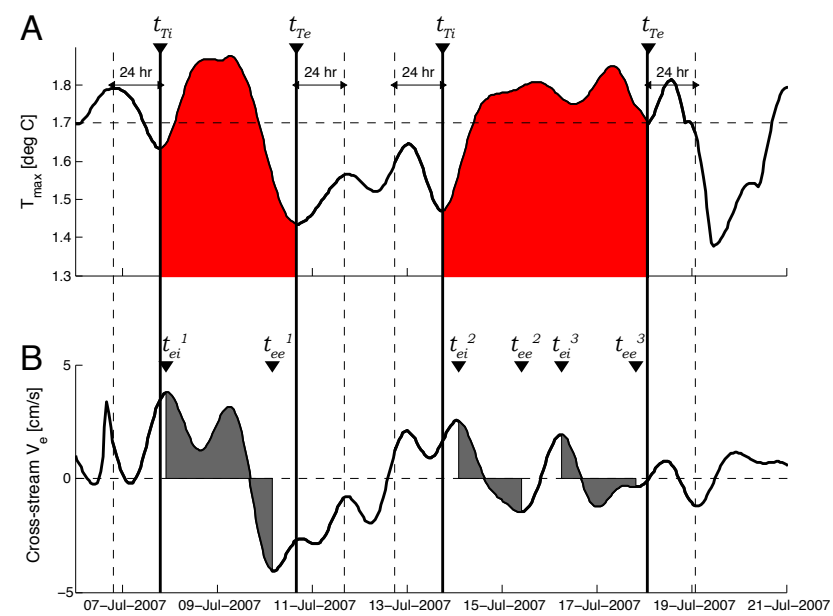

C

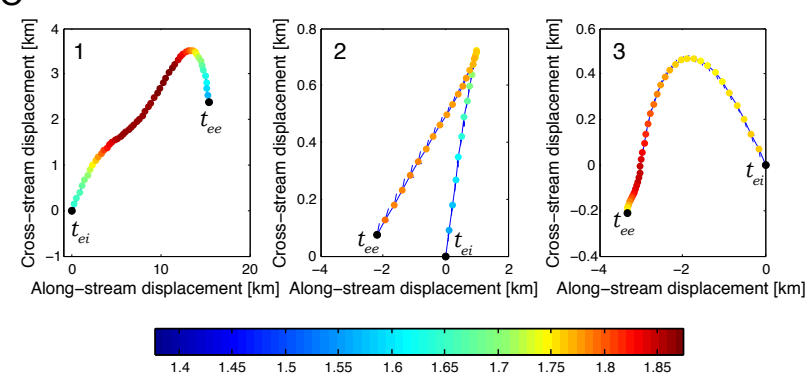

Fig. 7. Example of detection scheme for two detected $T_{\max }$ peaks - not the cleanest examples in the records, but rather a case of one eddy followed by the much more rare case of two eddies. (A) Time series of $T_{\max }$, showing the search windows $\Delta t_{T}=\left(t_{T \mathrm{i}}-24 \mathrm{~h}\right.$, $t_{T \mathrm{e}}+24 \mathrm{~h}$ ) for two detected peaks in $T_{\max }$. (B) The cross-stream eddy velocity over the same time intervals with the chosen bounds for the ith eddy, denoted by $\Delta t_{v}^{i}=\left(t_{\mathrm{ei}}^{i}, t_{\mathrm{ee}}^{i}\right)$, within corresponding $\Delta t_{T}$. (C) Progressive vector diagrams for the eddy velocity of the three eddies found in (B), summed over $\Delta t_{v}^{i}$ and color coded by $T_{\max }$.

for the eddy within $\Delta t_{T}$, color-coded by $T_{\max }$, is examined, to determine which of the extrema in the cross-stream eddy velocity are the proper ones to define the bounds of the eddy chord. An eddy should manifest as approximately U-shaped with a warm core. An example of the implementation of the method is shown in Fig. 7.

Eddies are drifting at the background velocity, $V_{\mathrm{bg}}$, past the mooring, thus an estimate of eddy diameter (actually, chord length) is $L_{\mathrm{e}}=V_{\mathrm{bg}} \Delta t_{v}$. Since we are seeking extrema in the cross-stream component of $V_{\mathrm{e}}$, we are effectively deriving metrics of the eddy core as opposed to the entire eddy. In some cases we are unable to cleanly detect the velocity signature of an eddy, though this does not necessarily mean that there is not an eddy present within that $\Delta t_{T}$.

Bathymetric tracking is consistent with a formation location of eddies at the slope-shelf break near mooring \#2 (location 300.160). Klinck et al. (2004) show that where Marguerite Trough intersects the shelf break, the shelf break 
Table 2. Number of eddies per year at mooring \#1, and their size.

\begin{tabular}{cccc}
\hline Year & $\begin{array}{c}\text { Number } \\
\text { eddies }\end{array}$ & $\begin{array}{c}\text { Mean diameter } \pm \\
\text { standard error }(\mathrm{km})\end{array}$ & $\begin{array}{c}\text { Median diameter } \\
(\mathrm{km})\end{array}$ \\
\hline 2007 & 35 & $8.2 \pm 1.0$ & 7.6 \\
2008 & 40 & $9.9 \pm 1.4$ & 6.4 \\
2010 & 37 & $10.2 \pm 0.9$ & 9.9 \\
\hline
\end{tabular}

itself projects to the west into the oncoming ACC, driving the ACC into the northern wall of the trough generating a pressure head that drives UCDW into the trough. This disturbance may also generate eddies, or at least advect eddies along with the mean-flow. If the eddies observed at mooring \#1 (300.100) are generated at mooring \#2 (300.160), they would likely have the same radius. Likewise, if they were drifting with the average current, tracking bathymetry (in this case topography along the northern wall), they would have drifted over mooring \#1 at a similar rate, giving a similar $d Q / d t$ - as observed.

Estimates for all eddy diameters yield Gaussian-like distributions (skewed toward larger $L_{\mathrm{e}}$, as expected for chords approaching the true diameter). Table 2 presents the number of eddies per year at mooring \#1 as well as their diameters' (in km) mean, median and standard error of the mean for all 3 years. The calculations suggest approximately 3 eddies per month, though as stated before, this is a lowerbound on the true number of eddies in the record. Through a few assumptions we can extend this to an estimate of the total number of eddies in a given year. Namely, we assume any time $T_{\max } \geq 1.7^{\circ} \mathrm{C}$ there is an eddy present at the mooring, and also assume that the mean temporal extent of the observed eddies is representative of the mean value for all eddies. This allows us to evaluate the ratio

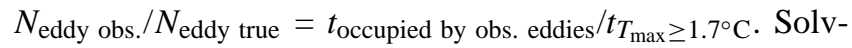
ing for $N_{\text {eddy true }}$ gives about 4-5 per month. This number is in good agreement with observations by Moffat et al. (2009) and idealized model simulations (St-Laurent et al., 2012).

We examine 23 CTD casts (since 1993) at mooring site \#2 (within a $4 \times 4 \mathrm{~km}$ square centered at 300.160 ), representative of the slope where we believe the eddies are generated. The first internal Rossby radius, $L_{R}=\left[g^{\prime} h_{1} h_{2} /\left(h_{1}+h_{2}\right)\right]^{1 / 2} / f$, for a two-layer system with layer thicknesses $h_{1}=170 \mathrm{~m}$ and $h_{2}=320 \mathrm{~m}-\mathrm{a}$ good approximation for this Antarctic water column - gives $L_{R}=4.8 \pm 0.08 \mathrm{~km}$. The eddies at mooring \#1 have yearly median diameters of $6.4-10 \mathrm{~km}$. Unless the eddies pass perfectly centered over the mooring, our "diameter" will actually be a chord length, and thus less than the true diameter. The eddy characteristics are consistent with $L_{R}$ at the shelf break. This is consistent with St-Laurent et al. (2012) who argue that the eddy-like structures noticed by Moffat et al. (2009) in this region are likely the result of baroclinic instabilities within the along-slope current.
The $Q$-series at mooring \#3 (400.100) shows considerably fewer eddy signatures. Their temperature core is slightly less than that of the events at mooring \#1 but does show episodic warming. Should the flow at mooring \#1 (Fig. 6) follow the bathymetric path implied, we would expect some eddies to be advected towards mooring \#3. The less apparent velocity signatures there suggest that eddies may quickly become sheared and diffuse over the shelf. Nevertheless, eddies at that site are not investigated since this study focuses on how the UCDW enters the shelf from the ACC waters over the slope. At mooring \#4 (460.046), $T_{\max }$ never exceeded $1.4^{\circ} \mathrm{C}$ and at mooring \#6 (230.-035), $T_{\max }$ was consistently less than $1^{\circ} \mathrm{C}$.

\subsection{Overflow of canyons}

Klinck et al. (2004) show from SO GLOBEC data (20012003) that UCDW enters Marguerite Trough (the major canyon crossing the WAP shelf). If this water then overflows the trough onto the nominal shelf floor, we would expect to see a signal of ocean heat increasing from the bottom of the mooring upward. Mooring \#1 is well positioned to test this mechanism, being adjacent to the northeastern wall of Marguerite Trough. We carefully examined all of the 1-houraveraged temperature profiles for the 3 years of mooring data adjacent to the Marguerite Trough and observed this behavior only once (and even that was equivocal), suggesting that this mechanism is not active.

\subsection{Upwelling}

MSISV08 showed that the increase in ocean heat content on the WAP shelf (using the 1993-2004 LTER January shipboard CTD data) showed a positive covariation with the depth of the pycnocline: elevated pycnoclines (interpreted as upwelling) correlated to increased ocean heat to the extent that $87 \%$ of the variance of ocean heat could be ascribed to upwelling.

We also know from this study that the correspondence between the elevated pycnocline and $Q$ may just as well describe stretching and squeezing of the lower water column due to eddy boluses passing the site, so this mechanism described in MSISV08 cannot differentiate the $87 \%$ described $Q$ variance due to upwelling from that due to eddies.

In theory, upwelling due to coastal winds (southwesterlies would be required) would drive a surface flow offshore and a deep flow onshore. Even though we have conditions suggesting upwelling is not an active mechanism (average winds along the WAP coast are not favorable to set up wind-driven upwelling and the nominal depth of the shelf at $450 \mathrm{~m}$ is rather deep for Ekman suction to operate as required (Klinck and Dinniman, 2010)), we cannot independently evaluate this mechanism. 


\subsection{Episodic advective diversions of the ACC}

\subsubsection{Shelf-wide flooding}

The previously adopted view of UCDW intrusions based on low-temporal resolution hydrographic surveys (e.g., Prezelin et al., 2004) is that intrusions of UCDW are spatiallylarge, hence the appeal of shelf-wide flooding as an explanatory mechanism. However, warm-core eddies that become sheared and diffuse over the shelf would manifest as warm tongue-like features in low-temporal resolution sampling even though the mechanism responsible is fundamentally different.

If shelf-wide flooding events are a mechanism moving warm ACC waters onto the shelf, we would expect to see them as lagged coherent events in $Q(t)$ across the entire mooring array. We do see lagged correlation between moorings \#5 and \#1, $20 \mathrm{~km}$ apart, but have shown that the correlative features are eddies. We do not see correlation of $Q$ across the complete mooring array as expected for a shelfwide event, thus eliminating this mechanism.

\subsubsection{Bathymetry-dependent intrusions}

Dinniman et al. (2011) find significant correlations between the along-inner-slope transport and a model dye flux within Marguerite Trough yielding intrusions of UCDW at the same time scales as the eddies observed at our moorings. One physical mechanism they propose to explain this correlation and the underlying intrusions is momentum advection. The shelf geometry near Marguerite Trough features a seaward bend which, if the along-slope flow is strong enough, may not allow the flow to bend with the topography and may force it into Marguerite Trough (Dinniman et al., 2011; Dinniman and Klinck, 2004). While this argument was applied explicitly to observations within the trough, our mooring is sampling flow to the nominal shelf along the eastern wall of the trough (the $T_{\max }$ layer is shallower than the minimum depth of the trough). The vertical extent of the influence of a slope canyon (in this case, Marguerite Trough) is dependent on the stratification and the width of the canyon (Allen and de Madron, 2009), with lower stratification more conducive to onflow. The very low stratification of the region (small $L_{R}$, calculated above) suggests that this should not be a problem for our mid-depth observations.

Using our background velocity $V_{\mathrm{bg}}$, we compute correlations with the onshore component of this advective flow and integrated heat content at mooring site \#1 computed from hourly profiles. It is important to note that by our definition of $V_{\mathrm{bg}}$, these correlations will necessarily be gauging covariance at frequencies lower than the time scale of eddyvariability. For compatibility, we smooth $\mathrm{Q}$ as the first mode of a singular spectrum analysis with an embedding dimension of $121 \mathrm{~h}$, the same as that used on the velocity $V_{\mathrm{bg}}$. Maximum correlations are $0.47,0.45$, and 0.27 for years 2007 ,
2008 , and 2010, respectively, at lag times ranging from 57 days and angles from -5 to +10 degrees relative to the onshore direction. While not overwhelmingly strong (but years 2007-2008 significant at $\alpha=0.01,2010$ significant at $\alpha=0.08$ ), these correlations suggest some degree of correlation between the magnitude of the onshore component of the advective flow and heat content. These correlations are stronger than correlations between velocity components and observed temperature values recorded on the eastern wall of the trough by Moffat et al. (2009) who concluded no relationship between those variables. The lag time may be explained by momentum advection. A requirement for that process is the background circulation provide a "suction" to carry the intrusion along onto the shelf. As an intrusion begins, by continuity the velocity anomaly will necessarily reach the mooring before the temperature anomaly does.

These results are not inconsistent with the delivery of heat to the nominal shelf via small baroclinic eddies. St-Laurent et al. (2012) show through stability theory that an unstable jet will generate appropriately sized eddies through baroclinic instability at the right temporal frequency, and then show through an idealized model that such eddies are advected along the trough's eastern wall within the corresponding background flow. We suspect that the eddies may be advected in eddy-rich intrusions periodically penetrating along the trough's eastern wall. This is in good agreement with the time series of $Q$ (Fig. 4), which show distinct low-frequency variability with near-constant-slope increases (i.e., the eddies) superimposed, as well as with our eddy-picking scheme that showed that several of the larger peaks in the $Q$ series were in fact the cumulative effect of several eddies arriving in sequence.

\section{Conclusions}

The evidence presented here strongly favors eddies as the mechanism for delivering warm (UCDW) water to the continental shelf. The presence of UCDW-core eddies is consistent with the observations of Moffat et al., 2009.

Distinct jumps in ocean heat content ( $Q$-events) at midshelf mooring \#1: (1) show remarkably consistent $d Q / d t$ over three years of observations, suggesting bathymetric steering of similar sized eddies over the mooring site; (2) coincide with mid-depth warm water boluses that show distinct rotation (usually anticyclonic) with the core water warmer than $1.7^{\circ} \mathrm{C}$, which is found only in UCDW within the ACC at the shelf break where UCDW is delivered via the ACC; (3) are related to eddies, with the larger chord lengths (closer to a true diameter) consistent with the Rossby radius at the shelf break where the eddies were presumably formed; (4) occur with frequency of 3-5 per month.

These features, along with projected trajectories at mooring \#1 that suggest bathymetric steering following the canyon wall (even on the northern fork of Marguerite 
Trough), allow a reasonable estimate of the eddy generation site. The presence of a warm core and the similarity between $L_{\mathrm{e}}$ at site \#1 and $L_{R}$ at site \#2 suggest that the eddies are of ACC origin, specifically generated by instabilities at the shelf-break. Bathymetric tracking suggests they enter the shelf where the NE wall of Marguerite Trough intersects the shelf-break at our site of mooring \#2. This constraint to follow the NE wall of the trough guides the onshore current, advecting them past moorings \#5 and \#1 (thus similar $d Q / d t$ ). The eddies may be advected within eddy-rich intrusions.

Changes of the ACC could influence the transport of UCDW onto the shelf. The thermal wind relation requires the rise of isopycnals towards the slope, and greater speed of the ACC may be associated with changes in the vertical shear and shoaling of isopycnals associated with CDW. Proximity of the ACC frontal jet to the shelf can also be important for generating baroclinic instabilities and generating intrusions (St-Laurent et al., 2012). Finally, given the eddy saturation of the ACC (Hogg et al., 2008), increases in the wind forcing may not adjust ACC transport or isopycnal tilt but instead increase its eddy kinetic energy (Böning et al., 2008). While these are not influences we could test with our mooring array, their potential impacts on the future transport of UCDW in a changing environment warrant further attention.

Acknowledgements. We acknowledge the LTER scientific teams, our shipboard mooring team (Matthew Erikson (team leader), Michael Garzio, Megan Cimino and Kate Ruck), the captain and crew of the RVIB L. M. Gould and RPSC for excellent field support in the deployment, recovery, servicing and redeployment of the moorings. As always, Rich Iannuzzi's contribution to this project is immeasurable; he prepares the replacement mooring parts (e.g., new string with sensor locations marked, etc.), and performed much of the actual data analysis; he also contributed invaluable scientific and editorial insights. Finally, this project would not have been possible without support from the entire LTER field team, frequently participating in the recovery and redeployments of the moorings and the crew of the LM Gould and Raytheon support personnel. This work was supported by NSF grants ANT-0701232, 0217282 and 0523261 . This work was done in cooperation with the Palmer Long Term Ecological Research project, and is Pal LTER contribution number 0409, and Lamont-Doherty Earth Observatory contribution number 7509. This IPY SASSI project has ended, but the moorings have been picked up by our LTER project affording more years of analyses and insights.

Edited by: D. Martinson

\section{References}

Allen, S. E. and Durrieu de Madron, X.: A review of the role of submarine canyons in deep-ocean exchange with the shelf, Ocean Sci., 5, 607-620, doi:10.5194/os-5-607-2009, 2009.
Böning, C. W., Dispert, A., Visbeck, M., Rintoul, S. R., and Schwarzkopf, F. U.: The response of the Antarctic Circumpolar Current to recent climate change, Nat. Geosci., 1, 864-869, 2008.

Cook, A. J., Fox, A. J., Vaughan, D. G., and Ferrigno, J. C.: Retreating glacial fronts on the Antarctic Peninsula over the past half-century, Science, 308, 541-544, 2005.

Dinniman, M. S. and Klinck, J. M.: A model study of circulation and cross-shelf exchange on the west Antarctic Peninsula continental shelf, Deep-Sea Res. Pt. II, 51, 2003-2022, 2004.

Dinniman, M. S., Klinck, J. M., and Smith Jr., W. O.: A model study of Circumpolar Deep Water on the West Antarctic Peninsula and Ross Sea continental shelves, Deep-Sea Res. Pt. II, 58, 15081523, 2011.

Ducklow, H. W., Clarke, A. W., Dickhut, R., Doney, S. C., Geisz, H., Huang, K., Martinson, D. G., Meredith, M. P., Moeller, H. V., Montes-Hugo, M., Schofield, O., Stammerjohn, S. E., Steinberg, D., and Fraser, W.: The Marine Ecosystem of the West Antarctic Peninsula, in: Antarctica: An Extreme Environment in a Changing World, edited by: Clarke, A., Johnston, N. M., Murphy, E. J., and Rogers, A. D., Wiley-Blackwell, London, 121-159, 2012.

Hofmann, E. E., Wiebe, P., Costa, P., and Torres, J. J.: An overview of the southern ocean global ocean ecosystems dynamics program, Deep Sea Res. Pt. II, 51, 1921-1924, 2004.

Hogg, A. C., Meredith, M. P., Blundell, J. R., and Wilson, C.: Eddy heat flux in the Southern Ocean: Response to Variable Wind Forcing, J. Climate, 21, 608-620, 2008.

Klinck, J. M. and Dinniman, M. S.: Exchange across the shelf break at high southern latitudes, Ocean Sci., 6, 513-524, doi:10.5194/os-6-513-2010, 2010.

Klinck, J. M., Hofmann, E. E., Beardsley, R. C., Salihoglu, B., and Howard, S.: Water-mass properties and circulation on the west Antarctic peninsula continental shelf in austral fall and winter 2001, Deep Sea Res. Pt. II, 51, 1925-1946, 2004.

Lilly, J. M, and Rhines, P. B.: Coherent eddies in the Labrador Sea observed from a mooring, J. Phys. Oce., 32, 585-598, 2002.

Martinson, D. G., Stammerjohn, S. E., Iannuzzi, R. A., Smith, R. C., and Vernet, M.: Western Antarctic Peninsula physical oceanography and spatio-temporal variability, Deep Sea Res. Pt. II, 55, 1964-1987, 2008.

Moffat, C., Owens, B., and Beardsley, R. C.: On the characteristics of Circumpolar Deep Water intrusions to the west Antarctic Peninsula Continental Shelf, J. Geophys. Res., 114, C05017, 1$16,2009$.

Orsi, A. H., Whitworth, T., and Nowlin, W. D.: On the meridional extent and fronts of the Antarctic Circumpolar Current, Deep Sea Res. Pt. I, 42, 641-673, 1995.

Pawlowicz, R., Beardsley, B., and Lentz, S.: Classical tidal harmonic analysis including error estimates in MATLAB using T_TIDE, Comput. Geosci., 28, 929-937, 2002.

Prezelin, B. B, Hofmann, E. E., Klinck, J. M, and Mengelt, C.: The linkage between Upper Circumpolar Deep Water (UCDW) and phytoplankton assemblages on the west Antarctic Peninsula continental shelf, J. Marine Res., 58, 165-202, 2000.

Prezelin, B. B., Hofmann, E. E., Moline, M., and Klinck, J. M.: Physical forcing of phytoplankton community structure and primary production in continental shelf waters of the Western Antarctic Peninsula, J. Marine Res., 62, 419-460, 2004. 
Rignot, E., Bamber, J. L., van den Broeke, M. R., Davis, C., Li, Y., van de Berg, W. J., and van Meijgaard, E.: Recent Antarctic ice mass loss from radar interferometry and regional climate modeling, Nat. Geosci., 1, 106-110, 2008.

Smith, R. C., Baker, K. S., Fraser, W. R., Hofmann, E. E., Karl, D. M., Klinck, J. M., Quetin, L. B., Prézelin, B. B., Ross, R. M., Trivelpiece, W. Z., and Vernet, M.: The Palmer Pal LTER: A long-term ecological research program at Palmer Station, Antarctica, Oceanography, 8, 77-86, 1995.
St-Laurent, P., Klinck, J. M., and Dinniman, M. S.: On the role of coastal troughs in the transport of ocean heat to ice shelves, J. Phys. Oceanogr., in revision, 2012.

Vaughan, D. G.: How does the Antarctic ice sheet affect sea level rise?, Science, 308, 1877-1878, 2005.

Webb, L.: Deep waters melting West Antarctica Ice Sheet Fringe mirror global ocean exponential warming, Columbia University Masters Thesis (unpublished), 2011. 